\title{
Erratum to: First human use of hybrid synthetic/biologic mesh in ventral hernia repair: a multicenter trial
}

\author{
James G. Bittner IV ${ }^{1} \cdot$ Kevin El-Hayek ${ }^{2,3} \cdot$ Andrew T. Strong ${ }^{2} \cdot$ \\ Melissa Phillips LaPinska ${ }^{4} \cdot$ Jin S. Yoo ${ }^{5}$ Eric M. Pauli ${ }^{6}$. \\ Matthew Kroh ${ }^{2,3,7}$
}

Published online: 21 September 2017

(C) Springer Science+Business Media, LLC 2017

\section{Erratum to: Surg Endosc \\ DOI 10.1007/s00464-017-5715-6}

On page 1, right-hand column, first paragraph, second sentence from bottom: "6.8\% (95\% CI 2.2-16.6\%)" should be changed to "7.4\% (95\% CI 2.4-17.8\%)".

On page 3, right-hand column, second paragraph, first sentence: "With 59 (93.6\%) patients available for followup at 12 months, the hernia recurrence rate was $6.8 \%(95 \%$
CI 2.2-16.6\%)" should be changed to "With 55 (87.3\%) patients available for follow-up at 12 months, the hernia recurrence rate was $7.3 \%$ (95\% CI 2.4-17.8\%)".

On page 5, right-hand column, third paragraph, second sentence: "6.8\%" should be changed to "7.3\%".

On page 6, Table 5, changes were made in the Event, Recurrence, and Mortality rows as well as in the footnotes. The correct version of Table 5 is displayed.

The online version of the original article can be found under doi:10.1007/s00464-017-5715-6.

\footnotetext{
Matthew Kroh

Mkroh@ClevelandClinicAbuDhabi.ae

1 Department of Surgery, Virginia Commonwealth University School of Medicine, Richmond, VA, USA

2 Department of General Surgery, Digestive Disease and Surgery Institute, Cleveland Clinic, Cleveland, OH, USA

3 Department of Surgery, Lerner College of Medicine of Case Western Reserve University, Cleveland, OH, USA

4 Department of Surgery, University of Tennessee Graduate School of Medicine, Knoxville, TN, USA

5 Department of Surgery, Duke University School of Medicine, Durham, NC, USA

6 Department of Surgery, The Pennsylvania State University College of Medicine, Hershey, PA, USA

7 Digestive Disease Institute, Cleveland Clinic Abu Dhabi, Abu Dhabi, United Arab Emirates
} 
Table 5 Surgical site events and morbidity at 12 months postoperatively

\begin{tabular}{lllll}
\hline Event & All Hernia & Incisional & Ventral & $P$ value \\
\hline SSE $(\%)^{\mathrm{a}}$ & 39 & 52.4 & 5.9 & $<0.01$ \\
Seroma & 23.7 & 33.3 & 0 & $<0.01$ \\
Seroma + PI & 8.5 & 9.5 & 5.9 & 1.00 \\
Hematoma & 0 & 0 & 0 & 1.00 \\
Hematoma + PI & 1.7 & 2.4 & 0 & 1.00 \\
Wound dehiscence + PI & 1.7 & 2.4 & 0 & 1.00 \\
SSI & 0 & 0 & 0 & 1.00 \\
SSI + PI & 3.4 & 4.8 & 0 & 1.00 \\
Recurrence $(\%)^{\mathrm{b}}$ & 7.3 & 7.3 & 7.1 & 1.00 \\
Mortality $(\%)^{\mathrm{b}}$ & 1.8 & 2.4 & 0 & 1.00 \\
\hline
\end{tabular}

Incisional and ventral data compared using Fisher's exact test $(\alpha=0.05)$

SSE surgical site event, PI procedural intervention, SSI surgical site infection

${ }^{a}$ All calculated based on 59 patients (42 incisional and 17 ventral) available at 6-month follow-up

${ }^{\mathrm{b}}$ Both calculated based on 55 patients (41 incisional and 14 ventral) available at 12 -month follow-up 